\title{
The Semantic Component of the Evoked Potential of Differentiation
}

\author{
Chingis A. Izmailov, Svetlana G. Korshunova, and Yevgeniy N. Sokolov \\ Moscow State University
}

\begin{abstract}
This work analyzes data from recordings of (occipital and temporal) cortical evoked potentials (called evoked potentials of differentiation (EPD) occurring in humans in response to an abrupt substitution of stimuli. As stimuli we used three groups of words: the names of the ten basic colors taken from Newton's color circle; the names of seven basic emotions forming Shlossberg's circle of emotions; and seven nonsense words comprised of random combinations of letters. Within each group of word stimuli we constructed a matrix of the differences between the amplitudes of mid-latency components of EPD for each pair of words. This matrix was analyzed using the method of multidimensional scaling. As a result of this analysis we were able to distinguish the semantic and configurational components of EPD amplitude. The semantic component of EPD amplitude was evaluated by comparing structure of the data obtained to the circular structures of emotion and color names. The configurational component was evaluated on the basis of the attribute of word length (number of letters). It was demonstrated that the semantic component of the EPD can only be detected in the left occipital lead at an interpeak amplitude of P120-N180. The configurational component is reflected in the occipital and temporal leads to an identical extent, but only in the amplitude of a later (N180-P230) component of the EPD. The results obtained are discussed in terms of the coding of categorized, configurational, and semantic attributes of a visual stimulus.

Keywords: evoked potential of differentiation, multidimensional scaling, semantic component of EPD, visual categorization
\end{abstract}

Este trabajo analiza datos de registros (occipitales y temporales) de potenciales corticales evocados (llamados potenciales de diferenciación evocados-EPD) que ocurren en humanos como respuesta a una sustitución abrupta de estímulos. Como estímulos, se emplearon tres grupos de palabras: los nombres de los diez colores básicos tomados del círculo de color de Newton; los nombres de las siete emocionas básicas que forman el círculo de emociones de Shlossberg; y siete pseudo-palabras formadas por combinaciones de letras al azar. Para cada grupo de palabras-estímulo construimos una matriz de las diferencias entre las amplitudes de los componentes en la mitad de la latencia del EPD para cada pareja de palabras. Se analizó esta matriz con el método del escalonamiento multidimensional. Como resultado de este análisis, pudimos distinguir los componentes semánticos y configuracionales de la amplitud EPD. El componente semántico de la amplitud EPD se evaluó comparando la estructura de los datos obtenidos con las estructuras circulares de la emoción y de los nombres de los colores. El componente configuracional se evaluó mediante el atributo de la longitud de la palabra (número de letras). Se demostró que el componente semántico del EPD sólo puede detectarse en el electrodo occipital izquierdo en una amplitud inter-pico de P120-N180. El componente configuracional se refleja en los electrodos occipitales y temporales de forma idéntica, pero sólo en la amplitud de un componente más tardío (N180-P230) del EPD. Los resultados obtenidos se comentan en términos de la codificación de los atributos categorizados, configuracionales y semánticos de un estímulo visual. .

Palabras clave: potencial de diferenciación evocado, escalonamiento multidimensional, componente semántico del EPD, categorización visual

This work was supported by the Russian Scientific Humanitarian Foundation (project _ 04-06-00232 _ _ 07-06-00109).

Correspondence concerning this article should be addressed to Chingis A. Izmailov, Moscow State University, 4 Bolshaya Nikitskaya Ulitsa, Moscow (Russia). E-mail: ch_izmailov@mail.ru 
The spoken or written word, as a linguistic category, is very weakly linked to the physical characteristics of a stimulus word. Moreover, the semantic attributes of a word are only slightly liked with the configurational characteristics of the word-stimulus. Changes in font or orientation of letters, which can radically alter the geometric shape of a word, have no effect on the perception of its meaning. Given this isolation of the semantic attributes of a word from its physical features, special research interest accrues to the question of whether it is possible to specify the electrical brain activity related to this highly abstract feature of word stimuli.

The traditional approach to this problem is based on presentation of single stimuli with controlled physical, configurational and semantic features. The first study (Sutton, Braren, Zubin, \& John, 1965) to demonstrate the occurrence of a late positive component (which was designated as P300 or PS) of evoked potential when such cognitive features as stimulus uncertainty were varied, attracted researchers' attention for a number of reasons. First of all, this component was most pronounced in the bipolar leads (vertex-forehead or the monopolar lead from electrodes $\mathrm{Pz}$ and $\mathrm{Cz}$ (with neutral electrodes on the ear lobes) (Donchin, 1981). Secondly, it occurred in response to auditory and visual stimuli and was weakest in the projection areas of the cortex (Davis, Osterhammel, Wier, \& Gjerdingen, 1972; Kutas \& Hillyard, 1980) rather than in association areas. Third, it occurred in response to the sound of a word as well as to its visual representation. P300's occurrence in response to multimodal stimuli and its broad distribution along the scalp, on the one hand; and its reactions to novelty and emotional loading, on the other, suggested that its occurrence was more closely related to such subcortical structures as the hippocampus and thalamus than to the cortex (Yingling \& Hosobychi, 1984). Further research showed that occurrence of P300 is more likely to be associated with the probability of the stimulus occurring than with semantics (Kiroy \& Ermakov, 1998).

This was particularly clearly demonstrated in studies by Rudell (1991), which compared the two types potentials obtained in response to presentation of meaningful and nonsense words with differing probabilities of occurrence in the center of a screen and when there was some degree of shift in the frontal plain. One potential was recorded with bipolar leads along the central line, from the vertex-forehead electrodes, where P300 is usually recorded. The other in the occipital region from electrodes displaced upward (by 4-5 $\mathrm{cm})$ and to the left $(3-4 \mathrm{~cm})$ was recorded from the union point; in other words, in the association area of the visual cortex. Comparison of these evoked potentials showed that $\mathrm{P} 300$ is recorded only in response to the presentation of a stimulus when there is a shift from one stimulus to a different one. Furthermore it is evoked similarly by meaningful and nonsense words. However it does not occur to the presentation of words with a high probability of occurrence in the center of the screen. At the same time the occipital lead showed a completely different picture. This lead recorded a $\mathrm{P} 240$ potential only in response to meaningful stimuli, regardless of their probability of occurrence. This potential did not occur in response to nonsense words, although a visual EP typical of response to a pattern was recorded. On this basis, Rudell, rejected P300 as a component of category recognition and, in its place nominated the new component P240, which is recorded in the occipital lead.

Subsequent studies by Rudell and Hua (1995) and Martin-Loeches et.al. (Martin-Loeches, Hinojosa, GomezJarabo, \& Rubia, 2001) confirmed the association between this potential of recognition (RP) with the categorical attributes of stimuli. Unlike the traditional "statistical" approach to specifying the components of the EP in which, for a series of various complex stimuli (for example, faces and non-face objects, or positive and negative emotions) statistical differences in the recorded EP are obtained and used to support conclusions on the stimulus-specificity of the components or leads, works by Rudell (1991), Rudell and Hsia (1995), and Martin-Loeches et al.(2001) did not simply use various types of stimuli, but rather a series of stimuli ordered on the basis of certain attributes. They discovered a parameter of recorded EP's that was monotonically associated with change in the identified attribute. Thus, in the work by Martin-Loeches et al.(2001), a subject was shown 6 types of 2-syllable words that were identical in number of letters. The first type consisted of 20 words referring to animals (semantically significant stimuli). The second group contained 20 words referring not to animals but to other objects. These were semantically correct but not significant stimuli. These words were selected to all have approximately the same frequency of occurrence in Spanish. A third group of stimuli contained orthographically normal but semantically meaningless words. In these words, each syllable was well formed, but the syllable combination had no meaning. The fourth group of stimuli consisted of random combinations of the letters that formed the words in the first group, with those combinations that led to orthographically well formed syllables eliminated. The fifth group consisted of words of the first group with most of the letters cut in half vertically and the halves of different letters joined, but with one or two letters left unaltered in each word. And finally, the sixth group, which was used as a baseline stimulus, consisted of fragments of letters combined in random order. A conclusion regarding the semantic specificity of the evoked potential was drawn by identifying a monotonic association between the amplitude of the EP and changes in a particular stimulus attribute.

However, there remained the question of the extent to which the potential of recognition (RP) was specifically associated with semantic category. After all, a written word, like any other complex multidimensional stimulus, is not only a semantic, but also a perceptual object, since it is a structure (configuration, pattern) that exists in space. We can identify 


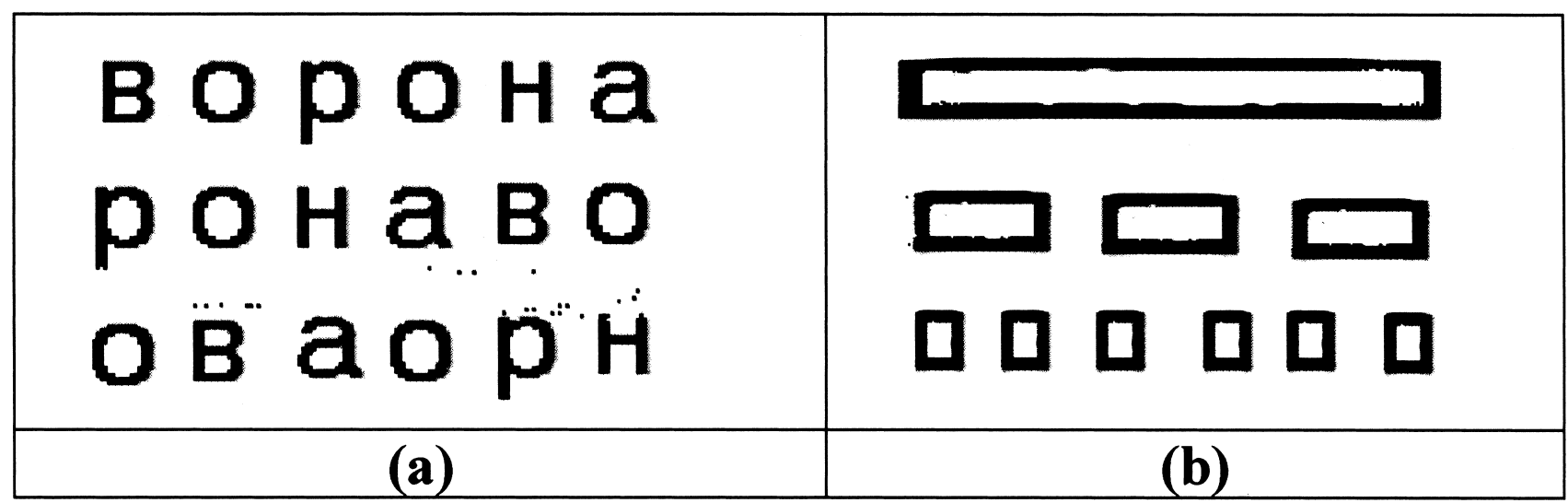

Figure 1. Three versions of the same six letters, a) top: word for crow; middle: same syllables scrambled; bottom: same letters scrambled (b) perceived configuration corresponding to variants in (a).

a whole series of features of this spatial structure. For example, when we transmuted the word " $"($ vorona $=$ crow $)$ (Figure 1) with respect to the attribute of semantic meaningfulness from a word to a random combination of its constituent syllables and then of the constituent letters of the word, as described in the work by Martin-Loeches et al. (2001), we identified a monotonic change in the stimulus not only with regard to linguistic features (word-syllable-letter), but also with regard to perceptual complexity (one unitthree units - six units), and with regard to the configurational feature of length of the stimulus - that is, the number of perceptual elements in the stimulus (respectively, six, three, and one). Since all these features are monotonically associated with each other it would be easy to attribute the recorded changes in brain activity to changes in the semantic component of the word, while actually the configurational component could be the more important component.

In the present work we describe another approach to specifying the semantic component of the $\mathrm{EP}$, one that is based on recording the evoked potential of differentiation (EPD) (Figure 2), which occurs in response to the abrupt substitution of one stimulus for another (Estevez \& Spekreijse, 1982; Paulus, Homberg, Cuninghum, Halliday, \& Ronde, 1985; Riggs \& Sternheim, 1969). Here the amplitude of EPD components corresponds to the magnitude of the perceived difference between the stimuli. It has been found that, as was the case for the EP to singly presented stimuli, it is possible to isolate components specific either to physical (intensity and spectral composition of radiated light) or configurational (orientation of lines, direction and extent of line angles, etc.) features of stimuli (Izmailov, Isaichev, Korshunova, \& Sokolov, 1998; Izmailov, Korshunova, Sokolov, \& Chudina, 2004; Izmailov \& Sokolov, 2004; Izmailov, Sokolov, \& Korshunova, 2005). At the same time, the method of recording EP in response to substitution of stimuli has significant advantages, since it does not require rigid control of stimulus characteristics identified a priori, which is especially difficult when one has to separate the semantic component (meaning of a word) form the configurational (purely pictorial aspects) in a complex visual stimulus.

The EPD recorded in response to the abrupt substitution of one word for another reflects the perceived holistic difference between the stimuli, which is detected by a wide variety of neuronal nets belonging to the visual system. The problem of dividing these up into specific components, reflecting the contributions of each of these nets, can be solved by analyzing the matrix of differences in potential between all possible pairs of stimuli, using the method of multidimensional scaling, in a way analogous to what is done with estimates of subjective differences between pairs of complex stimuli (Izmailov, 1980; Shepard, 1981; Shepard \& Carroll, 1966). The use of multidimensional scaling in the analysis of subjective estimates of differences between pairs of visual stimuli of various types demonstrates that it is possible to obtain an unambiguous/of uniform type solution for these data if the following conditions are met:

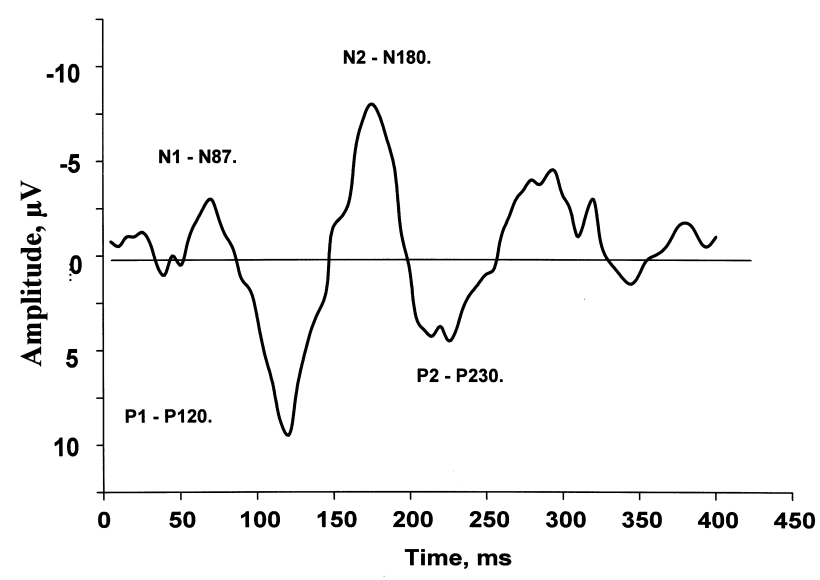

Figure 2. Visual evoked potential of differentiation (EPD), obtained in response to abrupt substitution of stimuli. Detailed description of its features may be found in the study by (Izmailov et al., 2005). 
1. The differences between stimuli pertain to a one dimensional perceptual variable (for example, color hue or saturation, orientation of a line in the frontal plane or size of the angle between two intersecting lines).

2. The construction of the geometric model is based on a condition of global linearity between the initial estimates of differences and interpoints distances (Shepard \& Carroll, 1966).

Under these conditions, the points representing the stimuli in Euclidean space always form a strictly circular trajectory (in the form of a circle or its parts), leading to this type of space being called a spherical model of differences between stimuli (Fomin, Sokolov, \& Vaitkyavichus, 1979; Izmailov, 1980; Sokolov \& Izmailov, 2006). Unlike Shepard, who explains this circularity with reference to the need to coordinate the structure of subjective experience with the physical structure of the environment (Shepard, 1987, 2001), we hypothesize that this circularity follows from the structure of the two-channel neuronal net that generates sensory representations of stimuli in the visual system (Izmailov, Sokolov, \& Chernorizov, 1989; Izmailov \& Chernorizov, 2005; Izmailov \& Sokolov, 1991). Thus, we may add to the traditional formal criteria, a substantive criterion for the correct solution: circularity in the structure of the differentiation data.

This criterion has made it possible to specify the physical (Izmailov, Isaichev, Korshunova, et al., 1998; Izmailov, Sokolov, \& Korshunova, 2005) and configurational (Izmailov, et al., 2004; Izmailov \& Chernorizov, 2005) components of the EPD. In a recent study (Izmailov, Sokolov\& Korshunova, 2005) we made an attempt to specify the components of EPD, including, in addition to the physical and configurational aspects, one more feature of visual stimuli, which could be referred to as expressive attributes. In this study the stimuli used were schematic faces in which gradual changes in the configurational features of the face (curvature of the mouth and slant of the brows) was accompanied by non-gradual (discrete) changes in the emotional expression of the face. However, when we analyzed the cortical EPD obtained in response to stimuli such as the emotional expression of faces, we encountered problems analogous to those found by MartinLoeches et al. (2001). The monotonic association between the configuration of the mouth, for example, and emotion conveyed was retained and this significantly impeded the potential for establishing an unambiguous interpretation of the EPD components with respect to the different attributes of the complex stimulus. To eliminate this problem, it is essential to select stimuli in which the configurational and semantic features are not only independent, but also inversely correlated.

\section{Method}

To attain this goal, the current study uses two classes of words for which there is a strong negative association between the semantic (meaning of the word) and configurational (number of letters in the word) features. These consisted of the basic emotions [Translator's note: numbers that follow English words are the number of letters in the Russian ]- happiness 7, surprise 9, fear 5, sadness 6 , disgust 10 , anger 4 , and calm 11 ; and the basic colors blue 5, blue-green 7, green 7, green -yellow7, yellow 6, orange 9 , red 7 , purple 9 , violet 10 and white 5 . In addition, as a control we used a third group of stimuli - nonsense words (pseudowords) formed in the following way. For each of the emotion names, the constituent letters were scrambled randomly so that the number of letters in the word remained the same. The semantic spaces representing the basic colors and emotions in the form of a circular trajectory on a plane are well known in the psychophysical literature as Newton's color circle for the color names and the Schlossberg circle for names of emotion (Frumkina, 1984; Izard, 1980; Izmailov \& Sokolov, 1992; Shepard \& Cooper, 1992; Strongman, 1978).On the basis of psychophysical experiments with these stimuli, we might have expected three possible solutions.

1. The EPD components specific to the configurational attributes of the stimuli would change monotonically as a function of a word's length, independently of its semantic (emotional or color-related) meaning.

2. The EPD components specifically related only to the semantic attributes of a word would not depend on the configurational features (word length, number of letters, etc.) but only on the semantic differences between words.

For example, the EPD for the two Russian words for happiness (7) and sadness (6) or the words red (7) and green (7) should have only a small amplitude for the configurational component since there are only slight differences in the number of letters, but a maximum difference for the semantic component. On the contrary, the amplitude of the EPD for the words for surprise (9) and fear (5) or the words blue (5) and violet (10) should be of low amplitude for the semantic component and high for the configurational.

3. Configurational and semantic differences could be reflected in the same components. In this case the amplitude of the EPD components would always be a combination of the two types of differences and the solution should be obtainable by means of constructing an integrated categorical space, where the two categories "word length" and "word meaning" would be projected on the two subspaces of a common space.

The nonsense words in our study serve as a control for appropriateness of multidimensional scaling for data analysis. Since the geometrical model constructed using this method has many degrees of freedom, all else being equal, the solution for nonsense words will make it possible to evaluate the validity of the solution obtained for the semantically meaningful words (Martin-Loeches et al., 2001). 


\section{Subjects}

Two women and one man, aged from 28 to 34 , participated in this experiment. One of the two women (a different one each time) and the man participated in each session involving presentation of meaningful words, for colors and emotions, and only the man participated in the control session with nonsense words. Thus, two subjects participated in each of the experimental (as opposed to control) sessions.

During each session, the subject sat, in a soft armchair with a back and head rest in a position he or she found comfortable, in front of a monitor screen, in the center of which (the subject's gaze fixation point) the word stimuli were presented. The subject was instructed to read each word to himself.

\section{Stimuli}

Stimuli were pairs of words consisting of letters of moderate brightness presented against a dark background in the center of the monitor screen. The heights of the letters in the words were the same. The words differed only in their length, that is, the number of letters (the configurational attribute of the stimulus) and their meaning (the semantic attribute). Each presentation included a pair of words randomly selected from the appropriate word set, which were substituted for each other abruptly 50 times. (There were a total of 90 word pairs in the first set of trials, and 42 pairs each in the second and third set.) The duration of presentation for each word in a pair varied from 800 to
$1200 \mathrm{~ms}$ to preclude a driving response. The total duration of the presentation of a single pair did not exceed 100 seconds. After each pair of stimuli had been presented the subject was allowed to rest for 15-20 seconds. Then the next pair was presented. A mark indicating the subject's gaze fixation point was presented for 1 second before each series of stimuli.

Figure 3 shows a sequence of events involved in the presentation of a stimulus pair and the points at which evoked potentials were recorded in response to the initial and reverse substitutions of the stimuli in the pair. The arrows with dotted lines show the onset of evoked potential recording $(60 \mathrm{~ms}$ before the moment of substitution). The white arrowheads correspond to substitution of the second (blue) word for the first (red), and the black arrowheads correspond to the reverse substitution. The evoked potentials were averaged separately for the initial type of change (50 records) and for the reverse type (50 records as well). The interpeak amplitudes corresponding to the two components (P120N180 and N180-P230) of these EP serve as quantitative measurements of the electrophysiological differences between a pair of stimuli, analogous to assessment of perceived differences (subjective distance) that a subject makes in psychophysical experiments. Because the difference (like the distance) is assumed to be symmetrical, theoretically these two average EP's should have the same amplitude as long as the two words in the pair are the same. But, as a consequence of both random and systematic errors they may differ from each other. For $n$ stimuli words we obtain a matrix of $n(n-1)$ pairs and a

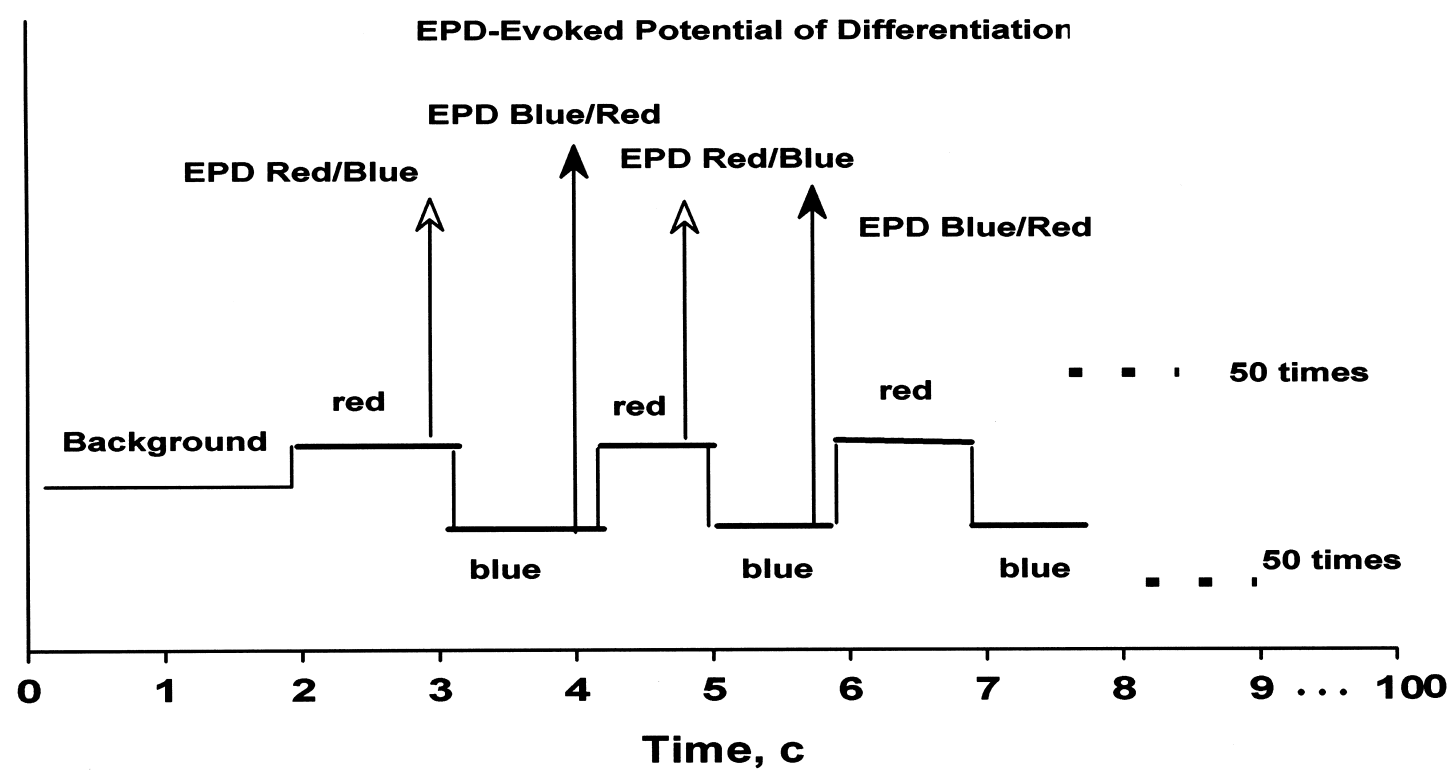

Figure 3. Schedule of stimulus presentation and EPD recording for a single pair of stimuli. (Detailed description in the text.) 
corresponding matrix of EP amplitudes for each EP component.

As an example, the amplitude matrix for the component P120-N180 obtained for one of the subjects in the session involving color names is presented in Table 1 . The rows of this matrix correspond to the word stimulus that was presented first in the paired presentation, and the columns to the second words in each presentation pair. Thus, the upper right triangle (relative to the main diagonal of the matrix) represents all the initial substitution (the difference between the potentials for the first and second stimuli in the pair), while the left lower triangle of the matrix depicts the reverse substitution (the difference between the second and first stimuli in the same pair).

This matrix shows that the symmetry of amplitudes is far from ideal, but, nevertheless, it is statistically significant (using a $t$-test). For this reason the paired sets of amplitudes were averaged and the square matrix was transformed into a triangular one (Table 2). The amplitude of the other subject's data was analyzed in precisely the same way and then the data for each subject were averaged.
Analysis of EPD amplitudes using multidimensional scaling. In accordance with the data obtained by Izmailov, et al. (2001), Izmailov, Solokov \& Korshunova (2005), and Izmailov et al. (2004), we used two interpeak amplitudes, namely P120-N180 and N180-P230, as our measures of interstimulus differences. Thus, our initial material for data analysis for each of the three groups of stimuli were the eight matrices of pairwise differences, two matrices for each of the four leads (O1, O2, T5, and T6). All 24 amplitude matrices were analyzed using Gutman's algorithm (Shepard, 1981; Shepard \& Carroll, 1966). For each matrix, analysis produced the coordinates of points corresponding to stimuli-color names, emotion names, and nonsense words-in a four dimensional Euclidean space. Four dimensions were selected in the context of the last of the three hypotheses considered in the theoretical introduction. The significance of these axes was evaluated on the basis of an acceptable intuitive interpretation of the spatial structure of the stimulus (Shepard, 1981; Shepard \& Carroll, 1966). In accordance with the conceptions of two-channel coding of each attribute in the visual system and a spherical model

Table 1

Initial Interpeak Amplitudes of Component P120-N180 of EPD (in Microvolts), Recorded in Lead O1, in Response to Substitutions of one Color Name for Another. Word Length is measured in Number of Letters. Data for a Single Subject, Averaged Over 50 Presentations of Each Stimulus Word Pair

\begin{tabular}{|c|c|c|c|c|c|c|c|c|c|c|c|c|}
\hline Color names & Word length & $\mathrm{N}^{\mathrm{o}}$ & 1 & 2 & 3 & 4 & 5 & 6 & 7 & 8 & 9 & 10 \\
\hline Blue & 5 & 1 & 0.0 & 6.8 & 10.4 & 8.2 & 6.4 & 8.2 & 6.9 & 6.4 & 9.1 & 9.5 \\
\hline Blue-green & 7 & 2 & 8.9 & 0.0 & 7.5 & 8.8 & 13.0 & 7.3 & 7.5 & 7.1 & 6.9 & 5.8 \\
\hline Green & 7 & 3 & 11.7 & 8.0 & 0.0 & 9.3 & 6.6 & 2.2 & 6.9 & 12.4 & 8.4 & 7.3 \\
\hline Green-yellow & 8 & 4 & 8.6 & 4.0 & 6.6 & 0.0 & 8.2 & 8.0 & 12.1 & 9.0 & 10.4 & 14.4 \\
\hline Yellow & 6 & 5 & 7.7 & 10.4 & 11.3 & 7.7 & 0.0 & 11.5 & 7.5 & 11.0 & 5.8 & 7.5 \\
\hline Orange & 9 & 6 & 13.0 & 6.4 & 6.0 & 9.9 & 17.0 & 0.0 & 15.5 & 2.9 & 4.7 & 6.4 \\
\hline Red & 7 & 7 & 10.8 & 6.9 & 4.4 & 8.2 & 5.5 & 7.5 & 0.0 & 4.4 & 6.4 & 5.8 \\
\hline Purple & 9 & 8 & 12.8 & 6.2 & 18.8 & 9.0 & 16.4 & 4.7 & 6.4 & 0.0 & 6.4 & 10.8 \\
\hline Violet & 10 & 9 & 14.8 & 7.3 & 8.4 & 13.0 & 7.3 & 3.1 & 5.5 & 4.7 & 0.0 & 14.1 \\
\hline White & 5 & 10 & 9.5 & 5.1 & 9.1 & 5.3 & 8.8 & 8.8 & 5.5 & 6.1 & 10.6 & 0.0 \\
\hline
\end{tabular}

Table 2

Data after Checking the Above Matrix for Symmetry and Averaging over Direction of Substitution

\begin{tabular}{|c|c|c|c|c|c|c|c|c|c|c|c|c|}
\hline Color names & Word length & $\mathrm{N}^{\mathrm{o}}$ & 1 & 2 & 3 & 4 & 5 & 6 & 7 & 8 & 9 & 10 \\
\hline Blue & 5 & 1 & 0 & & & & & & & & & \\
\hline Blue-green & 7 & 2 & 7.8 & 0 & & & & & & & & \\
\hline Green & 7 & 3 & 11.0 & 7.7 & 0 & & & & & & & \\
\hline Green-yellow & 8 & 4 & 8.4 & 6.4 & 7.9 & 0 & & & & & & \\
\hline Yellow & 6 & 5 & 7.1 & 11.7 & 8.9 & 7.9 & 0 & & & & & \\
\hline Orange & 9 & 6 & 10.6 & 6.8 & 4.1 & 8.9 & 14.2 & 0 & & & & \\
\hline Red & 7 & 7 & 8.8 & 7.2 & 5.6 & 10.1 & 6.5 & 11.5 & 0 & & & \\
\hline Purple & 9 & 8 & 9.6 & 6.6 & 15.6 & 9.0 & 13.7 & 3.8 & 5.4 & 0 & & \\
\hline Violet & 10 & 9 & 11.9 & 7.1 & 8.4 & 11.7 & 6.5 & 3.9 & 6.0 & 5.5 & 0 & \\
\hline White & 5 & 10 & 9.5 & 5.4 & 8.2 & 9.8 & 8.2 & 7.6 & 5.6 & 8.5 & 12.3 & 0 \\
\hline
\end{tabular}


of stimulus differences (Sokolov \& Izmailov, 1988; Izmailov, Isaichev, \& Shekhter, 1998) the spaces were centered so that the origin of the system of coordinates was located in the geometrical center of the configuration of points that was obtained. Next, starting with this origin, we looked for a position for the center for which the variance of radiusvector lengths of the points would be minimal. The smaller the variance of radii, the more the configuration of points would approach the surface of a sphere. Variance was evaluated as the ratio of the standard deviation of radiusvectors to the mean radius (coefficient of variation). The values of stress $(\mathrm{S})$, the mean radius $(\mathrm{R})$ and variability $(\mathrm{k})$ are given in Table 3 . The sphericity of the space was considered to be good when $\mathrm{S}<0.1$ and $\mathrm{k}<10 \%$ and unsatisfactory with $\mathrm{S}>0.2$ and $\mathrm{k}>20 \%$. As was stated above, in the data analysis these formal criteria were considered of secondary importance, we focused more on the substantive criteria of the semantic and configurational meaning of the results.

Definition of the dimensions of the stimulus differentiation space. Orthogonal rotation was used to orient each plane of the four-dimensional space so that one of the axes of the plane corresponded to the red-green opposition for color names, and the positive-negative opposition for names of emotions, and so that the point representing the word white and the emotion of calm would be as close as possible to the center of the plane. If we were able to solve this problem, then the first two coordinates of the space $\left(\mathrm{X}_{1} \mathrm{X}_{2}\right)$ were fixed and we moved on to the second problem-orienting the next plane in space (axes $\mathrm{X}_{3} \mathrm{X}_{4}$ ) so that the point representing the word with the smallest number of letters was located in the space as far as possible to the left along the horizontal axis, while the remaining points were ordered in accordance with the number of letters in the stimulus word. If we were unable to solve the first problem, we moved on to the solution of the second problem for the first two coordinates of the space and if we succeeded in solving it, considered only the two dimensional space, and considered the other two dimensions to be the result of experimental noise. If we could not solve the second problem, then we considered the amplitude in question to be non-informative both with regard to the semantic attribute and to the configurational one.

Table 3

Values of EPD Stress (S), Mean Radius (R) and Coefficient of Variation (K) Broken Down by EPD Component and Lead for Configurations of Points, Corresponding to Stimuli Words in a Geometric Model Obtained from EPD Amplitudes Recorded in Response to Substitution of: Color Name Words, Words Naming Emotions, and Nonsense Words. Column 2 cites the Minimal Number of Significant Coordinate Axes for the Stimulus Differentiation Space obtained from the Amplitude of the Given Component (Column 1)

COLOR NAME WORDS

lead

\begin{tabular}{|c|c|c|c|c|c|c|c|c|c|c|c|c|c|}
\hline \multirow[b]{3}{*}{ EPD Component } & \multirow{3}{*}{$\begin{array}{c}\text { Number } \\
\text { of axes } \\
\mathrm{Xi}\end{array}$} & \\
\hline & & \multicolumn{3}{|c|}{$\mathrm{O} 1$} & \multicolumn{3}{|c|}{$\mathrm{O} 2$} & \multicolumn{3}{|c|}{$\mathrm{T} 5$} & \multicolumn{3}{|c|}{ T6 } \\
\hline & & $S$ & $\mathrm{R}$ & $\mathrm{k}, \%$ & $S$ & $\mathrm{R}$ & $\mathrm{k}, \%$ & $S$ & $\mathrm{R}$ & $\mathrm{k}, \%$ & $S$ & $\mathrm{R}$ & $\mathrm{k}, \%$ \\
\hline P120-N180 & 4 & 0.06 & 1.08 & 5.4 & & & & & & & & & \\
\hline P120-N180 & 2 & & & & 0.25 & 0.96 & 29.2 & 0.21 & 1.04 & 15.6 & 0.18 & 1.04 & 12.6 \\
\hline N180-P230 & 4 & 0.03 & 1.09 & 20.0 & & & & & & & & & \\
\hline N180-P230 & 2 & 0.16 & 0.93 & 26.6 & 0.16 & 0.96 & 11.2 & 0.17 & 1.02 & 8.5 & 0.17 & 1.03 & 7.5 \\
\hline
\end{tabular}

WORDS NAMING EMOTIONS

\begin{tabular}{|c|c|c|c|c|c|c|c|c|c|c|c|c|c|}
\hline & & & & & & & & & & & & & \\
\hline & & \multicolumn{3}{|c|}{ O1 } & \multicolumn{3}{|c|}{$\mathrm{O} 2$} & \multicolumn{3}{|c|}{$\mathrm{T} 5$} & \multicolumn{3}{|c|}{$\mathrm{T} 6$} \\
\hline & & $\mathrm{S}$ & $\mathrm{R}$ & $\mathrm{k}, \%$ & $\mathrm{~S}$ & $\mathrm{R}$ & $\mathrm{k}, \%$ & $\mathrm{~S}$ & $\mathrm{R}$ & $\mathrm{k}, \%$ & $\mathrm{~S}$ & $\mathrm{R}$ & $\mathrm{k}, \%$ \\
\hline P120-N180 & 4 & 0.01 & 1.04 & 5.6 & & & & & & & & & \\
\hline P120-N180 & 2 & & & & 0.23 & 0.96 & 36.3 & 0.10 & 1.01 & 15.3 & 0.18 & 1.03 & 11.9 \\
\hline N180-P230 & 4 & 0.01 & 1.06 & 8.8 & & & & & & & & & \\
\hline N180-P230 & 2 & 0.13 & 0.76 & 11.5 & 0.11 & 1.04 & 18.2 & 0.10 & 0.99 & 13.3 & 0.16 & 0.99 & 10.6 \\
\hline
\end{tabular}

NONSENSE WORDS

\begin{tabular}{|c|c|c|c|c|c|c|c|c|c|c|c|c|c|}
\hline & & \multirow{2}{*}{\multicolumn{3}{|c|}{$\mathrm{O} 1$}} & & & & & & & \\
\hline & & & & & & & & \multicolumn{3}{|c|}{ T5 } & \multicolumn{3}{|c|}{ T6 } \\
\hline & & $S$ & $\mathrm{R}$ & $\mathrm{k}, \%$ & $S$ & $\mathrm{R}$ & $\mathrm{k}, \%$ & S & $\mathrm{R}$ & $\mathrm{k}, \%$ & $\mathrm{~S}$ & $\mathrm{R}$ & $\mathrm{k}, \%$ \\
\hline P120-N180 & 2 & 0.07 & 1.07 & 14.3 & 0.13 & 1.06 & 16.7 & 0.18 & 1.01 & 16.7 & 0.20 & 0.97 & 31.3 \\
\hline N180-P230 & 2 & 0.09 & 1.09 & 16.8 & 0.11 & 1.04 & 7.5 & 0.13 & 0.99 & 9.3 & 0.19 & 0.96 & 8.7 \\
\hline
\end{tabular}




\section{Procedure}

A detailed description of the recording procedure and a description of the equipment used may be found in the following works: Izmailov, Isaichev, Korshunova \& Sokolov 1998; Izmailov, Korshunova, \& Sokolov, 2001, Izmailov, Korshunova, Sokolov, \& Chudina, 2004; Izmailov, Sokolov, $\&$ Korshunova, 2005. The experiment being discussed here consisted of three series of word presentations-one each involving the names of colors, the names of emotions, and nonsense words.

\section{Results}

Figures 4-7 contain projections of the stimulus words on planes formed by pairs of axes of four dimensional space obtained for the two interpeak amplitudes P120-N180 and $\mathrm{N} 180-\mathrm{P} 230$, recorded in leads $\mathrm{O} 1, \mathrm{O} 2, \mathrm{~T} 5$, and $\mathrm{T} 6$ in response to substitutions in the names of colors, names of emotions and nonsense words.

Data for the first occipital lead O1. Figures $4 \mathrm{a}$ and $4 \mathrm{~b}$ show data obtained as a result of multidimensional scaling of the amplitudes of components P120-N180 and N180P230, respectively, recorded in the left occipital lead O1. The upper two graphs represent the projection of points corresponding to color names on two planes of a four dimensional space $X_{1} X_{2}$ and $X_{3} X_{4}$. The middle row of graphs shows the same thing for words designating emotions and the lower ones for nonsense words. The names of colors on the plane form a circular sequence (the Newton color circle) in a clockwise direction that fully accords with the positions of colors in the spectrum and the position of white in the center of the circle (Izmailov, 1980; Wyszeckl \& Stiles, 1982). An analogous picture was obtained for the names of emotions. Their circular sequence on the $\mathrm{X}_{1} \mathrm{X}_{2}$ plane corresponds to the sequence of emotions in the Shlossberg circle with the emotion calm at the center of the circle (Izard, 1980; Osgood, 1966; Strongman, 1978).

This means that the interpeak amplitude P120-N180 recorded in the occipital lead for the left hemisphere reflects the semantic content of word stimuli well. At the same time, the projection of these stimulus points on the plane formed by the two other axes (Figure 4a, graphs at the right) yields a structure that, on the whole agrees with the configurational attribute of the stimuli of word length (number of letters). For example, the color name words fall along axis $\mathrm{X}_{3}$ (upper right graph) so that the left-right sequence of words corresponds to increasing word length, although the points are chaotically located with respect to axis $\mathrm{X}_{4}$. However, the emotion name words (right middle graph) are ordered along both axes in such a way that the horizontal angle of the radius vector of a point on plane $\mathrm{X}_{3} \mathrm{X}_{4}$, starting from the shortest word (for anger in russian), increases monotonically in a clockwise direction corresponding to word length. It follows from this that the amplitude P120N180 contains not only information about the semantic differences among words, but also about configurational differences. This latter information is expressed in the amplitude P120-N180 less strongly than the semantic information. Words that occupy adjacent positions with respect to length (for example the Russian words for red (7 letters) and blue (5 letters) or for disgust (10 letters) and surprise (9 letters) may be reversed in the sequence. But the sequence of groups (short-intermediate - long) is always preserved.

This can be seen particularly clearly in the data on nonsense words (Figure 4, lower left). Because of the absence of semantic information in nonsense word stimuli, their configurational features are more prominent in the formation of this EPD component. The number of significant axes obtained for these stimuli is only two, the others proved to be a function of random experimental conditions. We see, that on the $\mathrm{X}_{1} \mathrm{X}_{2}$ plane of the four dimensional space, points form three compact groups on the basis of number of letters (indicated by numbers associated with each point) and the groups themselves form a clockwise circular sequence. These axes correspond in content to the $\mathrm{X}_{3} \mathrm{X}_{4}$ axes of the space obtained for the names of the emotions (middle right). At the same time, on the plane formed by the third and fourth coordinate axis of the space for nonsense words (Figure 4, lower right), the points are all randomly dispersed suggesting that these axes are not significant for a substantive analysis of the data.

Let us now consider another interpeak amplitude, that for N180-P230, for a later component of the EPD from lead O1, (Figure 4b). Here, as in Figure 4a, the upper two graphs are a projection of the color name points on two planes of the four dimensional space $\mathrm{X}_{1} \mathrm{X}_{2}$ and $\mathrm{X}_{3} \mathrm{X}_{4}$. The middle two graphs show the same projections for the emotion name stimuli, and the lower two for nonsense words. Unlike the data in $4 \mathrm{a}$, the points for all three types of stimulus are arranged only in accordance with word length on the $X_{1} X_{2}$ plane of the four dimensional space, which is reflected in the spherical model by horizontal angle (measured in the clockwise direction.) In this case, the arrangement of the points in a spherical trajectory is more exact than in Figure 4a. The groups of stimuli in Figure $4 \mathrm{~b}$, here take the form of separate points which occupy their proper places in the circular sequence. On the plane formed by the third and fourth axes of the space (on the right) the points are randomly located, indicating that the third and fourth axes are not relevant to a substantive analysis of the data.

Thus, the data obtained suggest that the occipital region of the left hemisphere can record potentials with a latency of $120-180 \mathrm{~ms}$, whose amplitude reflects mainly the semantic component of the visual stimuli. But they also to some extent reflect purely configurational differences 

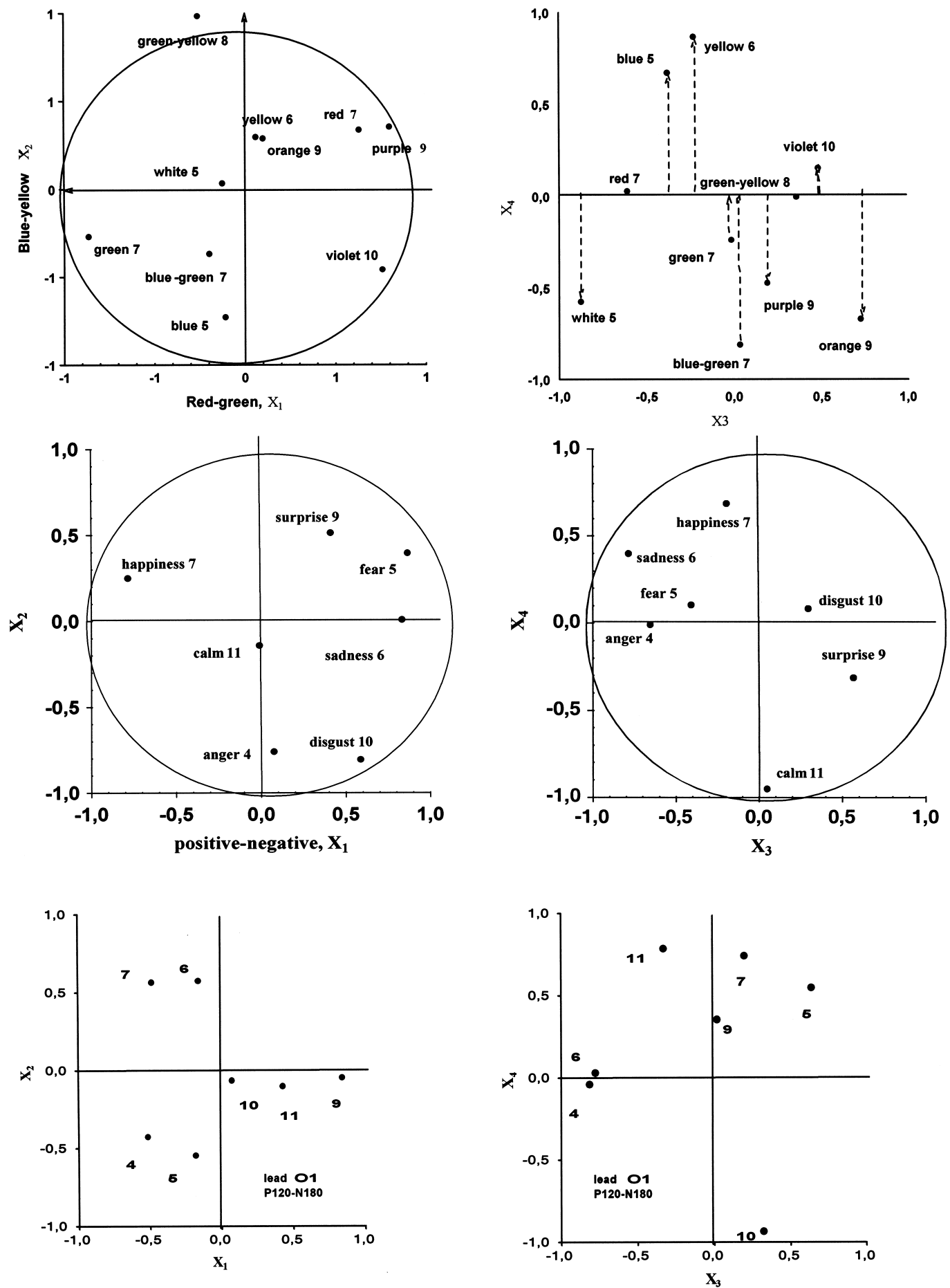

Figure 4a. Four-dimensional space of stimuli-words based on distances-amplitudes of component P120-N180 of the EPD recorded in the left occipital lead O1, in response to abrupt alternative substitution of stimuli. Upper row shows color name words, middle row shows emotion names, and lower row nonsense words. The left column shows the plane formed by the first two coordinate axes, and the right column that of the third and fourth coordinate axes. The circle drawn on some of the graphs indicates that the color or emotion names form a circular sequence, which is characteristic of Newton's color circle (upper-left graph) and Shlossberg's circle of emotion (middle-left graph). The middle-right graph represents circle in clockwise direction in accordance with number of letter in word. The nonsense words (left-bottom graph) fell into three clusters on the basis of number of letters in the word: short (4-5 letters), intermediate (6-7 letters), and long (9-11 letters), which also forms a (clockwise) circular sequence on the plane similar to that formed by words-emotion names. The bottom-right graph shows random location point-stimuli on the plane. It means that space of nonsense words has two dimensions only, connected with number of letters of the word. 

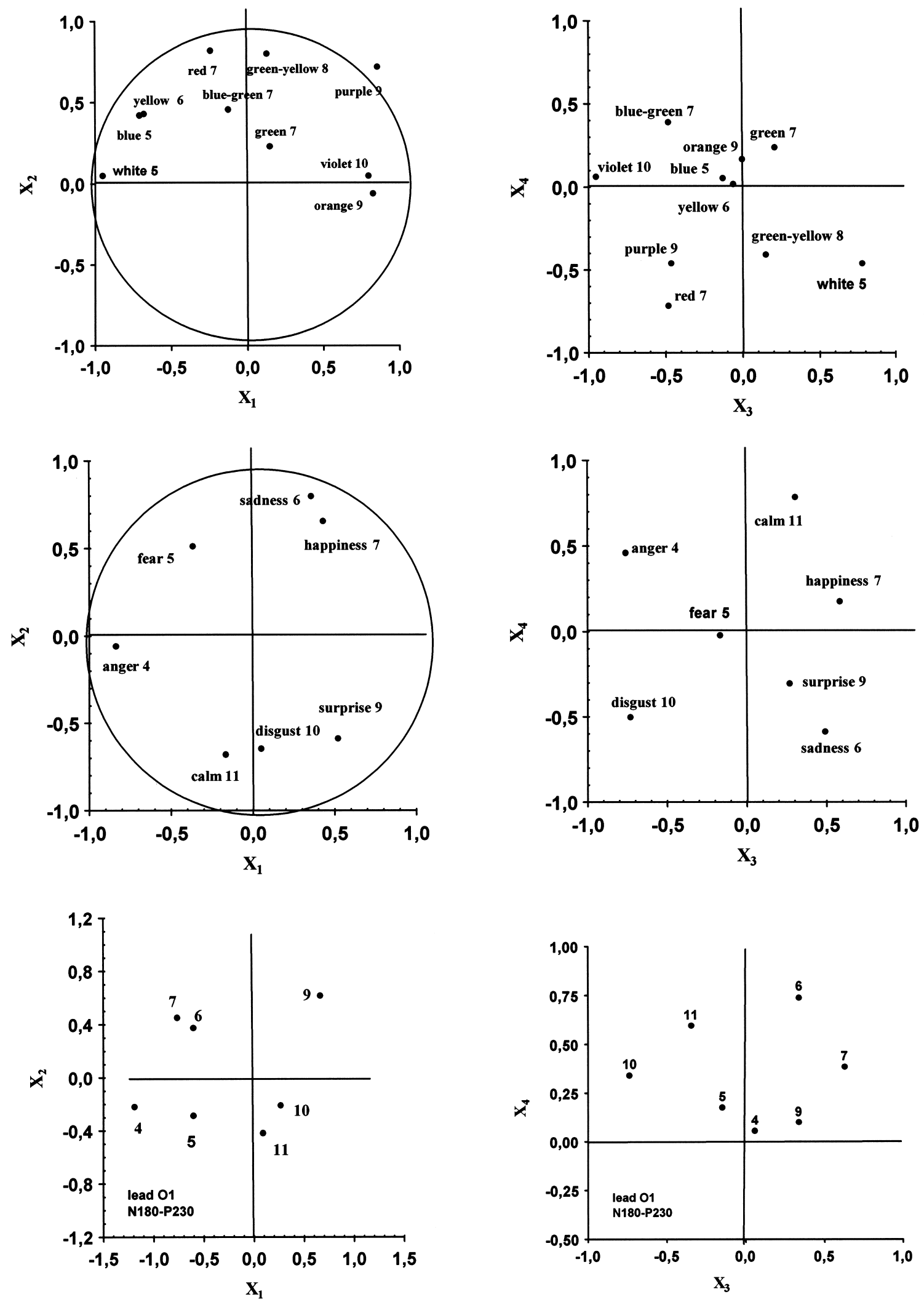

Figure $4 b$. Stimulus word space based on the amplitudes/distances of component N180-P230 of the EPD, recorded in the left occipital lead $\mathrm{O} 1$ in response to abrupt substitution of one stimulus word for another. The top row of graphs shows the space for color names, the middle row-names of emotions, and the bottom row nonsense words. The left column shows the space formed by the first two coordinate axes of the space and the right column - the space of the third and fourth coordinate axes. (Description in text.) 

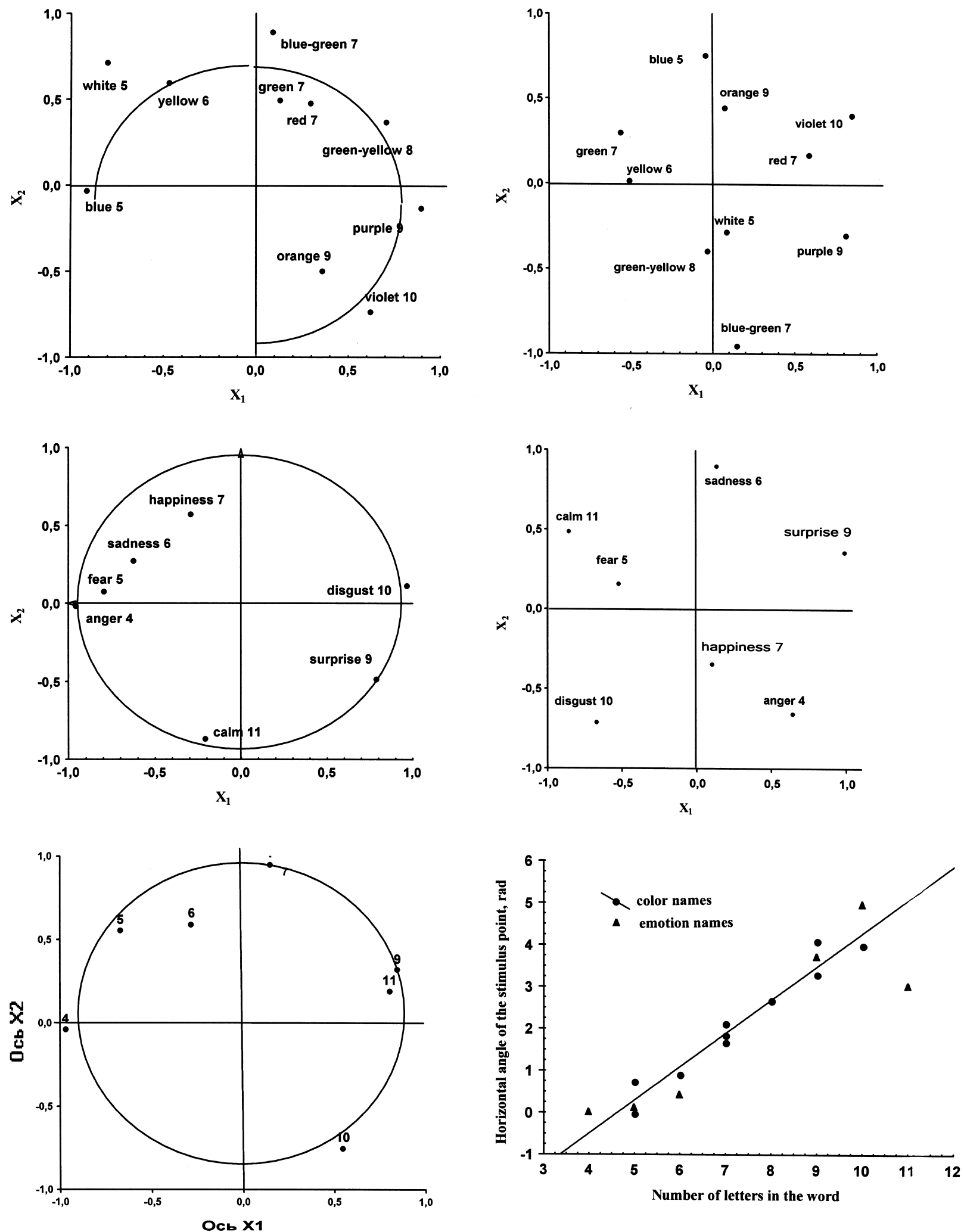

Figure 5. Stimulus word space based on amplitude of components P120-N180 (right column) and N180-P230 (left column) of the evoked potential of differentiation recorded in the right occipital lead $\mathrm{O} 2$ in response to abrupt substitution of one stimulus word for another. The upper and middle rows of graphs show words_-names of colors and names of emotions, respectively; the lower left graph shows nonsense words. The lower right graph shows the association between spherical coordinate as the horizontal angle of the stimulus point in twodimensional space (ordinate) and the number of letters in the word (abscissa). 

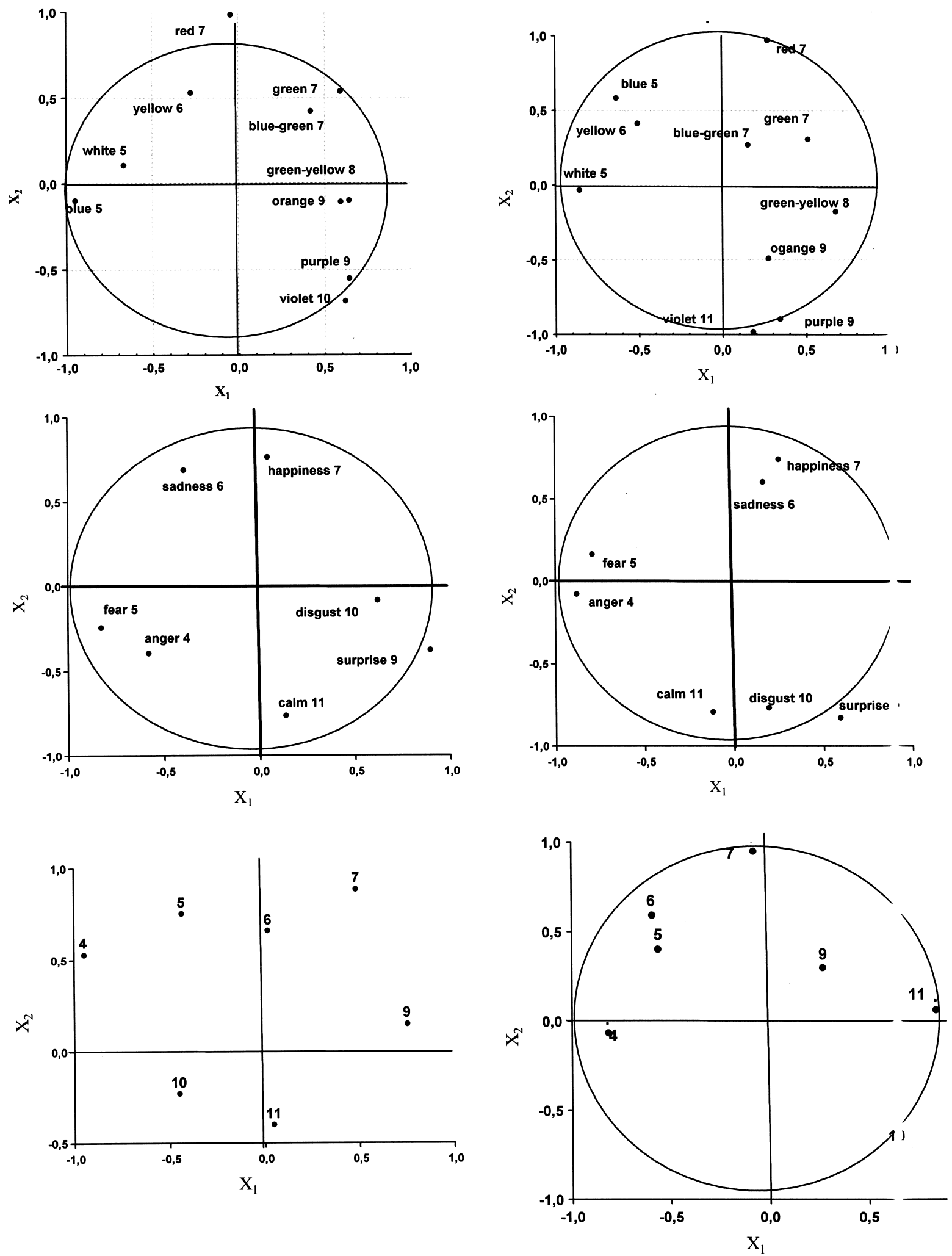

Figure 6. Space of stimulus words based on amplitude of components P120-N180 (left column) and N180-P230 (right column) of the evoked potential of differentiation recorded in the left temporal lead T5 in response to abrupt substitution of one stimulus word for another. The top row of graphs shows color name words, the middle row-names of emotions, and the bottom row, nonsense words. In all cases the circular (clockwise) sequence of points representing stimuli on the plane of the first two coordinate axes of the space corresponds only to word length (number of letters), and is not correlated with meaning. 

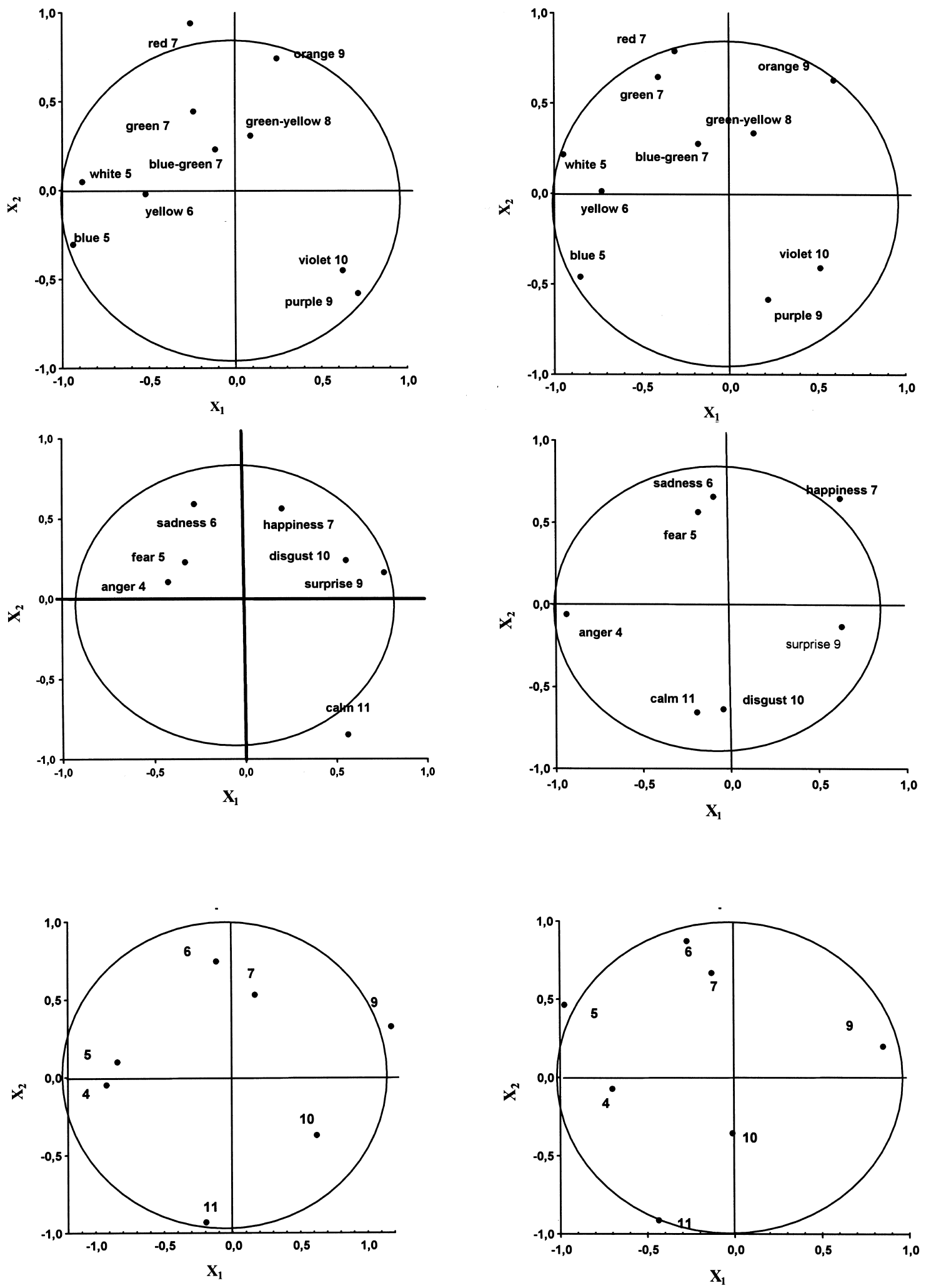

Figure 7. Space of stimulus words based on amplitude of components P120-N180 (left column) and N180-P230 (right column) of the evoked potential of differentiation recorded in the right temporal lead T6 in response to abrupt substitution of one stimulus word for another. The top row of graphs shows color name words, the middle row-names of emotions, and the bottom row, nonsense words. In all cases the circular (clockwise) sequence of points representing stimuli on the plane of the first two coordinate axes of the space corresponds only to word length (number of letters), and is not correlated with meaning. 
between stimuli. It is very important to note that the amplitude of the evoked potential is influenced, albeit to differing degrees, both by semantic and by configurational attributes of the visual stimuli. In the stimuli we used these attributes were rather simplified and isolated, and for this reason the method of multidimensional scaling of interstimulus differences allowed us not only to detect the contributions made by both but also to evaluate the contribution of each of them to the overall response. It may be hypothesized that in more complex stimuli (both with regard to configuration and semantics), even the method of multidimensional scaling will prove inadequate for dealing with this problem.

Data from the right occipital lead O2. Here the results of multidimensional scaling of EPD amplitude shows that the right visual cortex reacts to configurational differences between stimuli in the same way as the left cortex, while it fails to react at all to semantic differences. For this reason all the data are presented in the two dimensional configurational space. Figure 5 shows the position of stimulus points (color and emotion names) in the two dimensional space obtained for interpeak amplitudes P120N180 (upper and middle right) and N180-O230 (upper and middle left). Points in both the right graphs are chaotically arranged, they cannot be ordered either by word length or by meaning. At the same time the other, later amplitude N180-P230 (left graphs) shows a clear association with the graphic features of the stimuli. The points corresponding to words are ordered clockwise in accordance with word length, as was found for analogous data for the left hemisphere. The lower left graph in Figure 5 shows analogous results for nonsense words. It is evident that the stimulus points form a well-defined circular sequence ordered according to number of letters in the nonsense word. The right lower graph of this Figure shows the angular coordinates of the stimulus point as a function in radians of the number of letters in the word. The circles represent the color name data points and the triangles the names of emotions. The fact that this function is linear attests to the correctness of the hypothesis that the amplitude component N180-P230 reflects the configurational attributes of the stimuli not merely in a qualitative way (as was the case of lead O1) but quantitatively as well.

Data for temporal leads T5 and T6. Results of data analysis obtained for the temporal cortex are presented in Figure 6 (left hemisphere) and Figure 7 (right hemisphere). In both Figures, the left graphs show data obtained for interpeak amplitude P120-N180 and the right ones for the amplitude N180-P230. The upper graphs show data for color names, the middle ones for names of emotions, and the lower ones for nonsense words. Here, as in Figure 5, we provide a two dimensional solution since no systematic association with stimulus features could be found for the remaining axes of the four dimensional space. These graphs show what is essentially the same solution for both potential components as well as for both hemispheres. In all cases the trajectory of points has the form of a relatively welldefined circular trajectory ordered as a function of number of letters in the word.

\section{Discussion}

Detection of the configurational attributes of a visual stimulus. The results obtained support a conclusion that information about a configurational attribute of a stimulus such as length (spatial extent) is detected by neurons of both the occipital and the temporal cerebral cortex and is relatively precisely reflected in middle latency $(120-230 \mathrm{~ms})$ components of the EPD. It is noteworthy that, for the visual cortex, the configurational attributes of a word are more fully reflected in the later (180-230 ms) mid-latency components of the EPD, although, to a lesser extent, the influence of this attribute can be seen in the earliest midlatency component (120-180 ms).

This is consistent with the results of studies in which coding of cognitive information has been found to be associated not with potential P300, but with the mid-latency potential N170 (Jeffreys, 1996; Liu et al., 2000) and with the potential of recognition P240 (Rudell, 1991; Rudell \& Hua, 1995) recorded in the occipital region. The graphs in Figure $4 \mathrm{~b}$ and 5 show that this attribute is a simple onedimensional property that is detected by a two-channel neuronal net analogous to that demonstrated for the orientation of a line in the study by Izmailov et al. (2004). The question is to what extent can the potentials recorded in the occipital cortex be interpreted as potentials of recognition. Data in studies by Rudell (1991), Rudell and Hua (1995), Streit, Wolver, Brinkmeyer, Ihl, \& Gaebel (2000), Martin-Loeches et al. (2001), and our own data (Izmailov et al., 2004; Izmailov \& Sokolov, 2004; Izmailov et al., 2001; Izmailov, Sokolov, et al., 2005) show that such potentials are evoked in response to rather diverse configurational properties. It can be hypothesized that they are not specific to the individual features of a pattern, but rather, are a nonspecific response to simple configurational properties in general. This explains why, despite the significant number of studies in which various classes of stimuli groups within one class, and even individual stimuli evoke potentials that differ significantly within the limits of the analysis in a specific experiment, and yet at the same time data from different experiments cannot be associated with each other in a way that would enable use of combined data from various studies to obtain systematic information about the visual mechanisms of shape perception (Regan, 1972).

Many researchers associate the broad temporal range of the occipital cortex's responses to the presentation of a pattern with the hypothesis that there are two processes in the visual system: (a) categorization, identifying a stimulus as belonging 
to a certain class of stimuli, that is, sorting a number of stimuli into groups or clusters and (b) identification, recognition of a specific stimulus (Jolicoeur, Gluck, \& Kosslyn, 1984; Rosch, Mervis, Gray, Johnson, \& BoyesBraem, 1976; Sugase, Yamane, Ueno, \& Kawano, 1999). Categorization is based on a small number of basic, general attributes of the stimulus and thus takes less time than identification, which requires more detailed information and thus occupies more time. The data in Figures 4 and 5 are formally consistent with the hypothesis of a two-stage process. The amplitudes of the earlier component P120-N180 yield a cluster distribution of stimulus points on the plane, which can be interpreted as the result of categorization, while the amplitudes of component N180-P230 produce a space in which each stimulus is correctly identified on the basis of its individual position relative to the other stimuli. In the study by Izmailov et al. (2004) this result is interpreted somewhat differently -as a temporal reflection of the activity of visual modules in the form of two-channel neuronal nets detecting individual configurational properties of the stimulus. A geometric model of this net has the form of a twodimensional Euclidean space in which the Cartesian axes represent the two channels, the activity of which is reciprocally associated, so that the excitation of one channel is accompanied by the inhibition of the other, while total net activity is always constant. Because of this feature of the channels (coordinate axes) the stimulus points do not fill the entire Euclidean space, but form a circular trajectory within it. This is why this representation of two-channel neuronal nets is called a model of stimulus differentiation. The spherical coordinate of the stimulus points codes the change in the configurational attribute of the stimulus, as is shown in Figure 5 (lower right) for the amplitude of components N180-P230, coding word length

It is hypothesized that the first channel of this twochannel net, which is represented by axis $X_{1}$, contains, in addition to cells of the striatic cortex, a large number of cells of the retina and lateral geniculate body, while the second channel, represented by axis $\mathrm{X}_{2}$, essentially consists of cortical cells. In the earlier component of the potential of differentiation, P120-N180, the activity of the first channel is dominant and the amplitude of this component, while retaining its monotonic association with changes in the configurational features of the stimulus, does not correspond quantitatively to the magnitude of interstimulus differences. Mathematically this is expressed in the projection of all points on the $\mathrm{X}_{1}$ axis. In this case, on the scale of the $X_{1}$ axis, all the stimulus points will be grouped into clusters ordered along the axis, but within each cluster the position of the points will depend on random noise. Clustering of this type is shown in the upper right and lower left graphs of Figure 4a. Only the participation of cortical cells of the second channel (represented in the geometric model by axis $\mathrm{X}_{2}$ ), by virtue of inhibitory interaction with the cells of the first channel, forms a complete neural net for coding the configurational features of the given stimulus. This allows the visual system to obtain complete quantitative information and this information is reflected in the amplitude of the later component, N180-P230, Thus, our data are consistent with designation of the later of the midlatency components of EPD (N180-P230) as the configurational component. However, since it also reflects the activity of two-channel modules, detecting the most diverse properties of a pattern, it can scarcely be considered a recognition potential in the sense of stimulus identification. For this reason we refer to it as the nonspecific configurational component of the EPD, which reflects the activity of various neuronal nets that detect various configurational characteristics of the pattern viewed.

Categorical and semantic components of the EPD. Interpretation of components of the EPD as categorizing and configurational does not contradict their designation in the works mentioned above, as components of categorization and identification, but requires some refinement in the definition of these terms. The concept of categorization, in addition to referring to a process of generalization and grouping of stimuli on the basis of identified features, also has the meaning of naming or designating the group of stimuli with a single common name. For example, a set of various shades of red could be designated with the common name red and a set of various depictions of a face could be given the common name of cheerful. However, the words red or cheerful do not contain only the categorical aspect of the stimulus, but also the semantic, linguistic aspect. And in this instance the category is not a generalization of a group of stimuli, but a single stimuli-this word. Thus, one could ask whether the categorical stimulus component of EP can reflect not only the categorical attribute of the stimulus, but the semantic attribute as well? The circular trajectories of emotion and color names we obtained fails to answer this question, since this trajectory is equally appropriate to the general categorical attributes of words, given by the sequence in which these words are arranged along the trajectory, and to the detailed, quantitative attribute that defines the exact position of a word in a rigidly defined location in semantic space. The criterion we propose is based on the fact that the categorical structure of differentiation, while retaining the general circular ordering of stimuli in space, does not retain the quantitative relationships among stimuli in different categories or within a single category. However, in Figure 4a (upper left) the color name white is located in the center of the color circle, while the words for blue-green, yellow, and orange are closer to white than blue, green and red. This may be a consequence of the fact that the visual cortex distinguishes words not only on the basis of quality of color tone (i.e., hue), as a color category, but also on basis of the quantitative aspect of the color-saturation. Saturation of the spectral colors of blue-green, yellow and orange are 
half that of blue, green, and red and this corresponds to our data on the categorical and quantitative characteristics of the space of artificial color names (Izmailov \& Sokolov, 1992). It should be noted that the geometric structure of color names, based on the amplitude of EPD, as well as on semantic assessments of differences does not exactly reproduce the quantitative structure of the color space based on data from measurements of differences among colored light stimuli using psychophysical methods (Izmailov \& Sokolov, 1991; Shepard \& Carroll, 1966). However, it is in good accord with the geometric structure of the space of color differentiation based on the amplitudes of early components of EPD (N87 and N87-P120), obtained in response to abrupt substitution of light stimuli of different spectral components and intensities (Izmailov \& Sokolov, 2004; Paulus, et al., 1984; Riggs et al., 1969).

Thus, our data show that the earlier of the middle latency components of EPD (P120-N180) specifically reflects the semantic attributes of the stimulus words. At the same time, this EPD component also reflects the categorical attributes of word stimuli. This may be seen in Figure 5. The upper right graph shows that points representing color word falls into two non-overlapping groups representing the mid portion of the visible spectrum (blue-green, green, yellow) and the extreme portions (blue, violet, red, orange). Analogously the right middle graph in Figure 5 shows the division of emotion name stimuli into two non-overlapping groups representing strong (anger, joy, disgust) and weak (calm, surprise, sadness) emotions. Based on data on component R120-N180 of EPD presented in Figures 4 and 5, we may hypothesize that general categorical information is processed in the visual cortex of both hemispheres, but that semantic information is processed only in the left hemisphere.

Comparison of the EPD recorded in the visual and temporal cortex in response to substitution of word stimuli. Unlike the significant interhemispheric asymmetry of the visual cortex (Figures 4-5), the temporal cortex (Figures 6-7) shows virtually identical EPDs for both hemispheres. Moreover, both middle latency components of the EPD reflect only the configurational component of the stimulus word. The graphs in Figures 6 and 7 show very similar patterns of points in two-dimensional space in the form of a circular sequence in a clockwise direction. Clearly this sequence is a reflection of the same function that, in the lower right of Figure 5, is attributed to the detection of the configurational component of a word in the visual cortex. To facilitate comparison of EPD data recorded in the visual and temporal cortexes in response to substitution of word stimuli, we have tabulated all the results of our study in Table 4 . These results are very similar to the data we obtained when we recorded the responses of the visual and temporal cortexes to substitution of lines of different orientations (Izmailov et al., 2004), which are cited in Table 5. Although line orientation and word length are different configurational properties, they give rise to

Table 4

Distribution of Semantic, Configurational (Length), and Categorical (Clusters) EPD Elements among Components and Leads For EPD Recorded in Response to Substitution of Various Stimuli: Color Name Words; B) Words Naming Emotions, and C) Nonsense Words. Column 2 Cites the Number of Significant Coordinate Axes for the Stimuli Differentiation Space obtained from Amplitude of the given Component (Column 1)

\begin{tabular}{|c|c|c|c|c|c|}
\hline \multirow[b]{2}{*}{ Components } & \multirow[b]{2}{*}{ Axes, $\mathrm{Xi}$} & \multicolumn{4}{|c|}{$\begin{array}{c}\text { COLOR NAME WORDS } \\
\text { lead }\end{array}$} \\
\hline & & $\mathrm{O} 1$ & $\mathrm{O} 2$ & $\mathrm{~T} 5$ & T6 \\
\hline \multirow[t]{2}{*}{ P120-N180 } & $\mathrm{X}_{1} \mathrm{X}_{2}$ & Semantics & none & Length & length \\
\hline & $\mathrm{X}_{3} \mathrm{X}_{4}$ & Length (clusters) & & & \\
\hline \multirow[t]{3}{*}{ N180-P230 } & $\mathrm{X}_{1} \mathrm{X}_{2}$ & length & length & Length & length \\
\hline & & \multicolumn{4}{|c|}{ WORDS NAMING EMOTIONS } \\
\hline & & $\mathrm{O} 1$ & $\mathrm{O} 2$ & T5 & T6 \\
\hline \multirow[t]{2}{*}{ P120-N180 } & $\mathrm{X}_{1} \mathrm{X}_{2}$ & Semantics & none & Length & length \\
\hline & $\mathrm{X}_{3} \mathrm{X}_{4}$ & Length (clusters) & & & \\
\hline \multirow[t]{3}{*}{ N180-P230 } & $X_{1} X_{2}$ & length & length & Length & length \\
\hline & & \multicolumn{4}{|c|}{ NONSENSE WORDS } \\
\hline & & $\mathrm{O} 1$ & $\mathrm{O} 2$ & $\mathrm{~T} 5$ & T6 \\
\hline P120-N180 & $\mathrm{X}_{1} \mathrm{X}_{2}$ & Length (clusters) & none & Length (clusters) & Length (clusters) \\
\hline N180-P230 & $\mathrm{X}_{1} \mathrm{X}_{2}$ & length & length & Length & length \\
\hline
\end{tabular}


Table 5

Distribution of Categorical and Configurational Elements of EPD among Components and Leads for EPD Recorded on a Study in Response to Substitution of Lines of Varying Orientation (Izmailov et al., 2004)

\begin{tabular}{lccccc}
\hline Components & $\mathrm{i}$ & $\mathrm{O} 1$ & $\mathrm{O} 2$ & $\mathrm{~T} 5$ & $\mathrm{~T}$ \\
\hline $\mathrm{P} 120-\mathrm{N} 180$ & $\mathrm{X}_{1} \mathrm{X}_{2}$ & Orientation & Orientation & Orientation & Orientation \\
& & (clusters) & (clusters) & (clusters) & (clusters) \\
$\mathrm{N} 180-\mathrm{P} 230$ & $\mathrm{X}_{1} \mathrm{X}_{2}$ & Orientation & Orientation & Orientation & Orientation \\
\hline
\end{tabular}

entirely similar types of responses in the visual and temporal cortexes, where one might have expected stronger specificity of evoked potential with respect to various features of visual stimuli. As was noted above, the reason for this lack of specificity does not lie in the EP themselves. On the contrary, we see in the graphs presented in this article, that even the simplest indicator of cortical cell activity contains complete and relatively exact information about visual stimuli. The reason for this is that presentation of the "simplest" stimulus pattern evokes simultaneous activity in the visual system not only of neuronal modules associated with the detection of a given stimulus, but, also, of nonspecific neuronal nets, such as, those detecting novelty, change, etc. Like the feature detectors, these make a systematic, and even more powerful, contribution to the EP than the specific detectors of the visual system. This contribution can not be eliminated by averaging, as is done for background cortical activity. For a pattern in which the EP is generated by several configurational features, the problem becomes even more complicated.

For example, in one of our studies (Izmailov et al., 2005) the stimuli, schematic drawings of faces, were varied independently with regard to two features, angle of curvature of the line of the mouth and slope of the line of the brows. When we analyzed EPD amplitudes, using a method analogous to the procedure in the current experiment, we found that these amplitudes change not only as a direct function of each of the two independent primary features of the stimulus (the first and second axis of the space for the differences among schematic faces), but also, in exactly the same way, as a function of the "total angle of curvature" of the mouth plus that of the brow in the faces (third and fourth axes of the same space (Table 6). Furthermore, this "total angle" activates two independent configurational modules: one detects the face pattern considering the sign of the angles of the lines, according to the principal of algebraic summation, and the other does not take the sign into account and adds absolute values. In other words, a stimulus pattern composed of a fixed number of independent geometric variables may activate a number of the most diverse visual system neuronal modules, which detect not only these variables themselves, but other features that are derived geometrically from the primary variables of the stimulus. Each of these modules makes a contribution to EP amplitude, but measuring these contributions is an extremely complicated task, especially in the context of activation of nonspecific neuronal nets and the inherent noise of the visual system.

Semantic attributes are detected in the visual cortex more rapidly than configurational ones. Our results on the informational attributes of visual evoked potentials based on differentiation of stimuli differ somewhat from data based on VEPs obtained in response to presentation of single stimuli (Ivanitskiy \& Strelets, 1976; Ivanitskiy, Strelets, \& Korsakov, 1984). These studies of the informational content of evoked potentials that are correlated with psychophysical parameters in humans identified a three stage sensoryperceptual process associated with certain components of the evoked potential. During the first stage (with a latency of up to $200 \mathrm{~ms}$ ) the physical features of the stimulus are analyzed; in the second (up to $300 \mathrm{~ms}$ ) sensory and nonsensory information (feelings) are synthesized; and in the third the stimulus is categorized and its meaning recognized (more than $300 \mathrm{~ms}$, duration depending on the difficulty of the task being performed).

Table 6

Distribution of Categorical, Expressive and Configurational Elements among EPD Components and Leads for EPD Recorded in Response to Substitution of Schematic Faces (Izmailov et al., 2005)

\begin{tabular}{|c|c|c|c|c|c|}
\hline Components & $\mathrm{i}$ & $\mathrm{O} 1$ & $\mathrm{O} 2$ & T5 & T6 \\
\hline \multirow[t]{2}{*}{ PP120-N180 } & $\mathrm{X}_{1} \mathrm{X}_{2}$ & $\begin{array}{l}\text { Configuration } \\
\text { and Expression }\end{array}$ & $\begin{array}{c}\text { Expression and } \\
\text { Configuration }\end{array}$ & $\begin{array}{c}\text { Configuration } \\
\text { (clusters) }\end{array}$ & $\begin{array}{c}\text { Configuration } \\
\text { (clusters) }\end{array}$ \\
\hline & $\mathrm{X}_{3} \mathrm{X}_{4}$ & Configuration & Configuration & Configuration & Configuration \\
\hline \multirow[t]{2}{*}{ N180-P230 } & $X_{1} X_{2}$ & Configuration & (clusters) & Configuration & Configuration \\
\hline & $\mathrm{X}_{3} \mathrm{X}_{4}$ & Configuration & none & Configuration & Configuration \\
\hline
\end{tabular}


Our data, based on recording of EPD, also show that the analysis of the physical features of the stimulus (we called this the physical component of light radiation) and its transformation into the sensory features of a subjective image occurs in the visual system in two sequential stages, which are somewhat shorter than those identified above (120 and $230 \mathrm{~ms}$, respectively). At the same time, differentiation of the stimuli on the basis of "general" categorical features, in the form of clustering and discrimination of stimuli on the basis of "individual" categorical features (expressive for faces, or semantic for words), to do not overlap in time with the later temporal range, but, on the contrary, occur with a latency of 120 $180 \mathrm{~ms}$, that is, immediately after analysis of the physical features of the visual stimulus.

The fact that detection of the semantic stimulus component precedes that of the configurational one could be explained by analogy to the temporal precedence of the categorical component by postulating the initial occurrence of partial detection of a small set of basic features of the stimuli, followed by the detailed analysis required for the individual specification of the stimulus (Jolicoeur et al., 1984; Liu, Harris, \& Kanwisher, 2002). However, in our case the words differed not only as generalized categorical units, but also as individual stimuli each one differing quantitatively from every other with respect to semantics (in referring to a specific color, for example). Of course, when text is read, identification of the meaning of a word does not require individual reading of every one of the letters, most frequently the first few morphemes are sufficient for that purpose, and this is certainly true for the names of the basic emotions and colors. This is associated with the fact that, in the process of reading, identification of the meaning of such words is based on extensive linguistic practice (Chao \& Martin, 1999; Tanaka \& Taylor, 1999), that is, memory, learning, and other cognitive processes are included in semantic recognition. However, the participation of complex cognitive processes is unlikely in our experiment, since the stimulus words replaced each other rapidly and the evoked potential was recorded in the visual cortex. Thus we may assume that in our case we are speaking of visual perception per se, and not of memory or learning. This conclusion is also supported by the fact that there was no visual semantic information in the evoked potentials of differentiation for the temporal cortex leads, where the influence of complex cognitive processes is more likely.

\section{Conclusions}

The evoked potential of differentiation (EPD) recorded when one word naming a color or emotion is substituted for another that has a contradictory meaning, carries information both about the semantic and the configurational features of this stimulus. The semantic component of the stimulus recorded in the occipital region of the left hemisphere is more strongly represented in the features of the P120-N180 complex of the EPD, while the configurational (spatial extent) aspect shows up more clearly in N180-P230.

In addition to the left occipital region, information about the configurational characteristic of the stimulus is also coded in features of the EPD N180-P230 complex recorded in the temporal regions of both hemispheres.

The information we have obtained about the representation of the semantic component in the earlier middle latency component of the EPD recorded from occipital areas compared to the configurational component accords with results of our own previous experiments in which we used as stimuli lines of various orientations (Izmailov et al., 2004) and the schematic drawings of faces differing in emotional expression (Izmailov et al., 2005).

\section{References}

Chao, L., \& Martin, A. (1999). Cortical regions associated with perceiving, naming, and knowing about colors. Journal of Cognitive Neuroscience, 11, 25-35.

Davis, H., Osterhammel, P.A., Wier, C.C, \& Gjerdingen, D.B. (1972). Slow vertex potentials: Interactions among auditory, tactile, electric and visual stimuli. Electroencephalography and Clinical Neurophysiology, 33, 537-545.

Donchin, E. (1981). Surprise! Surprise? Psychophysiology, 18, 493-513.

Estevez, O., \& Spekreijse, H. (1982). The "silent substitution" method in visual research. Vision Research, 22, 681-691.

Fomin, S.V., Sokolov, E.N., \& Vaitkyavichus, G.G. (1979). Isskustvennye organy chuvstv [Artificial sensory organs]. Saint Petersburg: Nauka.

Frumkina, R.M. (1984). Tsvet, smysl, skhodstvo [Color, sense, similarity]. Moscow: Nauka.

Ivanitskiy, A.M., \& Strelets, V.B. (1976).Vyzvannyi potentsial i psikhofizicheskie kharakteristiki vospriatiya. Zhurnal vysshei nervnoi deiatelnosti, 24, 793-798.

Ivanitskiy, A.M., Strelets, V.B., \& Korsakov, I.A. (1984). Informatsionnye protsessy mozga i psikhicheskaya deiatelnost [Informational processes of the brain and psychic activity]. Moscow: Nauka

Izard, C. (1980). Emotsii cheloveka (Human Emotions). Moscow: Moscow State University Press.

Izmailov, Ch.A. (1980). Sfericheskaya model tsvetorazlicheniya [Spherical model of color discrimination]. Moscow: Moscow State University Press.

Izmailov, Ch.A., \& Chernorizov A.M. (2005). Yazyk vospriatiya i mozg [The language of perception and the brain]. Psikhologia. Zhurnal Vysshei shkoly ekonomiki, 2, 22-52.

Izmailov, Ch.A., Isaichev, S.A., Korshunova, C.G., \& Sokolov, E.N. (1998). Tsvetovoi i yarkostnyi komponenty zritelnykh 
vyzvannykh potentsialov u cheloveka [Color and brightness components of the visual evoked potentials in humans]. Zhurnal vysshei nervnoi deiatelnosti, 48, 777-787.

Izmailov, Ch.A., Isaichev, S.A., \& Shekhter, E.D. (1998). Dvukhkanalnaya model razlichenia signalov v sensornykh sistemakh [Dual channel model of signal discrimination in sensory systems]. Vestnik Moskovskogo Gosudarstvennogo Universiteta, Seria 14. Psihología, 3, 29-40.

Izmailov, Ch.A., Korshunova, S., \& Sokolov, E.N. (2001). Relationship between visual evoked potentials and subjective differences between emotional expressions in "face diagrams." Neuroscience \& Behavioral Physiology, 31, 529538.

Izmailov, Ch.A., Korshunova, C.G., Sokolov, E.N., \& Chudina, Yu.A. (2004). Geometricheskaia model razlichenia orientatsii linii, osnovannaia na subektivnykh otsenkakh i zritelnykh vyzvannykh potentsialakh [A geometric model of line orientation based on subjective estimates and visual evoked potentials]. Zhurnal vysshei nervnoi deiatelnosti, 54, 267279.

Izmailov, Ch.A., \& Sokolov, E.N. (1991). Spherical model of color and brightness discrimination. Psychological Science, 2, 249259.

Izmailov Ch.A., \& Sokolov, E.N. (1992). A semantic space of color names. Psychological Science, 3, 105-111.

Izmailov, Ch.A., \& Sokolov E.N. (2004). Subjective and objective scaling of large color differences. In C. Kaernbach, E. Schroger, \& H. Muller (Eds.), Psychophysics beyond sensation. Laws and invariants of human cognition (pp. 27-42). Mahwah, NJ/London: Erlbaum.

Izmailov, Ch.A., Sokolov, E.N., \& Chernorizov, A.M. (1989). Psikhofiziologia tsvetovogo zrenia [Psychophysiology of color vision]. Moscow: Moscow State University Press.

Izmailov, Ch.A., Sokolov, E.N., \& Korshunova, S.G. (2005). Multidimensional scaling of schematically represented faces based on dissimilarity estimates and evoked potentials of differences (EPD) amplitudes. The Spanish Journal of Psychology, 8, 119-133.

Jeffreys, D.A. (1996). Evoked potentials studies of face and objects processing. Visual Cognition, 3, 1-38.

Jolicoeur, P., Gluck, M.A., \& Kosslyn, S.M. (1984). Pictures and names: Making the connection. Cognitive Psychology, 16, $243-$ 275.

Kiroy, V.N., \& Ermakov, P.N. (1998). Electroentsefalogramma $i$ funktsionalnye sostoianiya cheloveka [EEG and functional states of humans]. Rostov na Donu: Rostov State Univeristy Press.

Kutas, M., \& Hillyard, S.A. (1980). Reading senseless sentences: Brain potentials reflect semantic incongruity. Science, 207, 203-205.

Liu, J., Harris, A., \& Kanwisher N. (2002). Stages of processing in face perception in MAG study. Nature Neuroscience, 5, 910916.

Liu, J., Higuch,i M., Marantz, A., \& Kanwisher, N. (2000). The selectivity of the occipitotemporal M170 for face. NeuroReport, 11, 337-341.
Martin-Loeches, M., Hinojosa, J.A., Gomez-Jarabo, G., \& Rubia, F.J. (2001). An early electrophysiological sign of semantic processing in basal extrastriate areas. Psychophysiology, 38, 114-124.

Osgood, C.E. (1966). Dimensionality of the semantic space for communication via facial expressions. Scandinavian Journal of Psychology, 7, 1-30.

Paulus, W.M., Homberg, V., Cuninghum, K., Halliday, A., \& Ronde, N. (1984). Color and brightness components of foveal visual evoked potentials in man. Electroencephalography and Clinical Neurophysiology, 58, 107-119.

Regan, D. (1972). Human brain electrophysiology: Evoked potentials and evoked magnetic fields in science and medicine. London: Chapman \& Hall.

Riggs, L.A., \& Sternheim, C.E. (1969). Human retinal and occipital potentials evoked by changes of the wavelength of the stimulating light. Journal of the Optical Society of America. 59, 635-640.

Rosch, E., Mervis, C.B., Gray, W.D., Johnson, D.M., \& BoyesBraem, P. (1976). Basic objects in natural categories. Cognitive Psychology, 8, 382-349.

Rudell, A.P. (1991). The recognition potential contrasted with the P300. International Journal of Neuroscience, 60, 85-111.

Rudell, A. P., \& Hua, I. (1995).The recognition potential latency and word image degradation. Brain and language, 51, 229241.

Shepard, R.W. (1964). Circularity in judgments of relative pitch. Journal of the Acoustic Society of America, 36, 23462353.

Shepard, R. (1981). Mnogomernoe shkalirovanie i nemetricheskie predstavlenia. Normativnye i deskriptivnye modeli priniatia reshenii [Multidimensional scaling and non-metric representation. Normative and descriptive models of decision making]. Materials of the Soviet-American Symposium (pp. 84-97). _oscow: Nauka.

Shepard, R.N. (1987). Towards a universal law of generalization for psychological space. Science, 237, 1317-1323.

Shepard, R.N. (2001). Perceptual-cognitive universals as reflections of the world. Behavioral and Brain Sciences, 24, 581-601

Shepard, R.N., \& Carroll. J.D. (1966). Parametric representation of nonlinear data structures In P. R. Krishnaiah (Ed.), Multivariate analysis (pp. 561-592). New York: Academic Press.

Shepard, R.N., \& Cooper, L.A. (1992). Representation of colors in the blind, color-blind, and normally sighted. Psychological Science, 3, 97-104.

Sokolov, E.N., \& Izmailov, Ch.A. (1988). Three-stage model of color vision. Sensory Systems, 2, 314-320.

Sokolov, E.N., \& Izmailov, Ch.A. (2006). Vyzvannye potentsialy $\mathrm{v}$ sfericheskoi modeli kognitivnykh protsessov [The evoked potentials in the spherical model of cognitive processes]. Neirokompiutery: razrabotka i primenenie, 4, 90-105.

Streit, M., Wolver, W., Brinkmeyer, J., Ihl, R., \& Gaebel, W. (2000). Electrophysiological correlates of emotional and structural face processing in humans. Neuroscience Letters, 278, 13-16. 
Strongman, K.T. (1978). The psychology of emotion. New York: Wiley. Sugase, Y., Yamane, S., Ueno, S., \& Kawano, K. (1999). Global and fine information coded by single neurons in the temporal visual cortex. Nature, 400, 869-873.

Sutton, S., Braren, M.M., Zubin, J.M., \& John, E.R. (1965). Evoked-potential correlates of stimulus uncertainty. Science, 150, 1187-1188.

Tanaka, J.W., \& Taylor, M. (1999). Object categories and expertise: Is the basic level in the eye of the beholder? Cognitive Psychology, 23, 457-482.
Wyszeckl, G.W., \& Stiles W.S. (1982). Color science, concepts and methods, quantitative data and formulas ( $2^{\text {nd }}$ ed.). New York/Toronto/Singapore: Wiley.

Yingling, C.D., \& Hosobychi, Y. (1984). Subcortical correlation of P300 in human. EEG and Clinical Neurophysiology, 59, 72-76.

Received February, 6, 2007

Revision received July, 17, 2007

Accepted September, 3, 2007 